\title{
Sero-Prevalence of Hepatitis B Virus Infection among Blood Donors: A Retrospective Study in the Kintampo Municipal Hospital, Ghana
}

\author{
Williams Walana ${ }^{*}$, Patrick Hokey ${ }^{2}$, Samuel Ahiaba ${ }^{3}$ \\ ${ }^{1}$ Department of Clinical Laboratory Sciences, School of Medicine and Health Sciences (SMHS), University for \\ Development Studies (UDS), Tamale, Ghana \\ ${ }^{2}$ Department of Medical Laboratory Technology, College of Health and Well-Being, \\ Kintampo, Ghana \\ ${ }^{3}$ Kintampo Municipal Hospital, Kintampo, Ghana \\ Email: walanawilliams@yahoo.com
}

Received 19 January 2014; revised 19 February 2014; accepted 26 February 2014

Copyright @ 2014 by authors and Scientific Research Publishing Inc.

This work is licensed under the Creative Commons Attribution International License (CC BY). http://creativecommons.org/licenses/by/4.0/

(c) (i) Open Access

\section{Abstract}

Background: Hepatitis B virus is one of the transfusion transmission infectious agents of public health relevance. Its prevalence varies across the globe. Establishing the sero-prevalence of the disease is critical to informing the direction of preventive and control strategies. Objective: The aim of this study therefore was to establish the hepatitis B surface antigen sero-prevalence among blood donors in the Kintampo municipality of Ghana. Methodology: This three-year hospital based retrospective study was conducted at the laboratory unit of the Kintampo Municipal Hospital. The laboratory uses one step immunochromatographic test kits to detect the presence of hepatitis $B$ surface antigen in the sera of blood donors. Records on blood donors were reviewed for hepatitis B sero-positivity. Results: A total of 3402 blood donors were studied, out of which 3238 (95.2\%) were males and $164(4.8 \%)$ were females. The overall sero-prevalence of hepatitis $B$ surface antigen was $9.6 \%(327 / 3402)$. Majority of the sero-positive donors were less than 40 years, with higher prevalence of $16.4 \%(35 / 214)$ in donors less than 20 years. The sero-prevalence in males and females was $9.7 \%(313 / 3238)$ and $8.5 \%(14 / 164)$ respectively. Conclusion: The Kintampo municipality has a relatively high prevalence of hepatitis $B$ among blood donors. The probability of hepatitis B viral infection was age inclined as the youth seem to be at greater risk of contracting the disease.

${ }^{*}$ Corresponding author.

How to cite this paper: Walana, W., Hokey, P. and Ahiaba, S. (2014) Sero-Prevalence of Hepatitis B Virus Infection among Blood Donors: A Retrospective Study in the Kintampo Municipal Hospital, Ghana. Open Journal of Medical Microbiology, 4, 64-69. http://dx.doi.org/10.4236/ojmm.2014.41007 


\section{Keywords}

\section{Hepatitis; Blood; Sero-Prevalence}

\section{Introduction}

Hepatitis B virus is among the common viral infectious agents of public health importance globally. An estimated two billion people are infected worldwide with approximately 350 million others suffering the chronic form of the disease [1]-[4]. In Africa, more than 50 million people are chronically infected, with mortality risk of about 25\%. The carrier rates of the virus in Sub-Sahara Africa range from 9\% - 20\% [5]. The prevalence rates of the disease range from $4.8 \%$ to $21 \%$ in Ghana [6].

The disease is caused by an enveloped, partial ssDNA virus [7]-[9]. Hepatitis B virus infects the liver. The liver functions are impaired whiles the virus replicates in the hepatocytes [10] [11]. Hepatitis and liver damage arise as a consequence of the immune response to the virus in the liver cells [12]. Hepatitis B virus is present in the blood, blood products and body fluids such as vaginal secretions, and in low concentrations in the of saliva of active carriers [13]. The average incubation period of the virus is 90 days from the time of exposure to onset of symptoms, but may vary from 6 weeks to 6 months [14] [15]. The transmission of the virus via blood and blood products has been of public health concern, particularly in developing countries where the issue of unsafe blood still remains a major challenge [16] [17].

The demand for safe blood or blood products in life-saving interventions is critical to avoiding non-curable infectious diseases. In transfusion transmitted HBV (TTHBV), the rate of infection is proportional to the frequency of transfusion. The only way to prevent TTHBV is to employ more sensitive method to screen blood prior to transfusion. There is limited data on the district distribution of the prevalence of the disease. The current study therefore focused on establishing retrospectively the prevalence of HBV among blood donor in the Kintampo municipality of Ghana.

\section{Methodology}

\subsection{Study Site}

The Kintampo North Municipal Hospital is the only hospital in the municipality located in Kintampo, the capital of the municipality. Kintampo is located within the Brong-Ahafo region of Ghana between latitude $8^{\circ} 45 \mathrm{~N}$ and $7^{\circ} 45 \mathrm{~N}$ and longitudes $1^{\circ} 20 \mathrm{~W}$ and $2^{\circ} 1 \mathrm{~W}$. The municipal capital contains the geographical center of the country. The municipal district covers an area of $5108 \mathrm{~km}^{2}$ and has a population of 95,480, with population density of 21.75 persons $/ \mathrm{km}^{2}$ [18].

\subsection{Study Design}

This retrospective study was conducted at the Laboratory unit if the Kintampo North Municipal Hospital. The hospital's laboratory uses one step immunochromatographic test kits to assay for HBsAg sero-positivity. All available archived results (from January 2010 to December 2012) on blood donation from the hospital's laboratory were reviewed. Data comprising age, sex and results of HBsAg test of blood donors were reviewed. The data were analyzed using Microsoft excel 2007 statistical package.

\section{Results}

The period under review saw a total of 3402 people donating blood at the Kintampo Municipal Hospital. Out of this number, 3238 (95.2\%) were males while 164 (4.8\%) were females, suggesting male to female ratio of approximately 20:1. The year on year sero-positivity of HBsAg for 2010, 2011 and 2012 were $11.0 \%, 9.6 \%$ and $8.2 \%$ respectively. The overall sero-prevalence of HBsAg was $9.6 \%$ (Table 1 ). Donors in age group $<20$ years had the highest prevalence of $16.4 \%(35 / 214)$ while donors in age group $\geq 40<50$ had the least prevalence of $5.9 \%(22 / 376)$. Somehow, the sero-prevalence of HBsAg among the donors declined with the advancement in age (Figure 1). The overall sero-prevalence of HBsAg among female donors was 8.5\% (14/164) while that 
among male donors was 9.7\% (313/3238) (Table 2).

\section{Discussion}

Ghana is among the countries endemic with hepatitis B and constant surveillance is critical to establishing the prevalence of the disease. This informed our current hospital based retrospective study on the sero-positivity of HBsAg among blood donors at the Kintampo Municipal Hospital, Ghana.

The study revealed that the current sero-prevalence rate of HBsAg among blood donors in the municipality is 9.6\% (Table 1). The endemicity of HBV infection has been classified as high (>8\%), intermediate (2\% - 7\%) and low $(<2 \%)$ prevalence [19] [20]. The prevalence rate recorded in the study indicates that the municipality has relatively high sero-prevalence of HBsAg, particularly among blood donors. Even though a downward trend of prevalence was observed in the study, it did not make any significant impact on the HBV endemicity of the study area. In areas were endemicity of HBV is high, transmission of the virus is mostly via vertical route or acquired during pre-school age [21]. This suggests that there is the need to step up efforts aimed at reducing mother to child transmission of the virus in the municipality. The insignificant year on year reduction in pre-

Table 1. Yearly sero-positivity and overall prevalence of hepatitis B surface antigen among blood donors at the Kintampo Municipal Hospital.

\begin{tabular}{ccccc}
\hline YEAR & $\begin{array}{c}\text { SAMPLES } \\
\text { SCREEN }\end{array}$ & $\begin{array}{c}\text { FEMALE } \\
\text { N (\%) }\end{array}$ & MALE N (\%) & $\begin{array}{c}\text { HBV POSITIVE } \\
\text { N (\%) }\end{array}$ \\
\hline 2010 & 1093 & $50(4.6)$ & $1043(95.4)$ & $120(11.0)$ \\
2011 & 1188 & $52(4.4)$ & $1136(95.6)$ & $114(9.6)$ \\
2012 & 1121 & $62(5.5)$ & $1059(94.5)$ & $92(8.2)$ \\
Total & $\mathbf{3 4 0 2}$ & $\mathbf{1 6 4}(4.8)$ & $\mathbf{3 2 3 8}(95.2)$ & $\mathbf{3 2 7}(\mathbf{9 . 6})$ \\
\hline
\end{tabular}

Table 2. Gender distribution of hepatitis B surface antigen seropositivity among blood donors in the Kintampo Municipal Hospital.

\begin{tabular}{cc}
\hline GENDER & PREVALENCE n/N (\%) \\
\hline FEMALE & $14 / 164(8.5)$ \\
MALE & $313 / 3238(9.7)$ \\
TOTAL & $\mathbf{3 2 7 / 3 4 0 2 ( 9 . 6 )}$
\end{tabular}

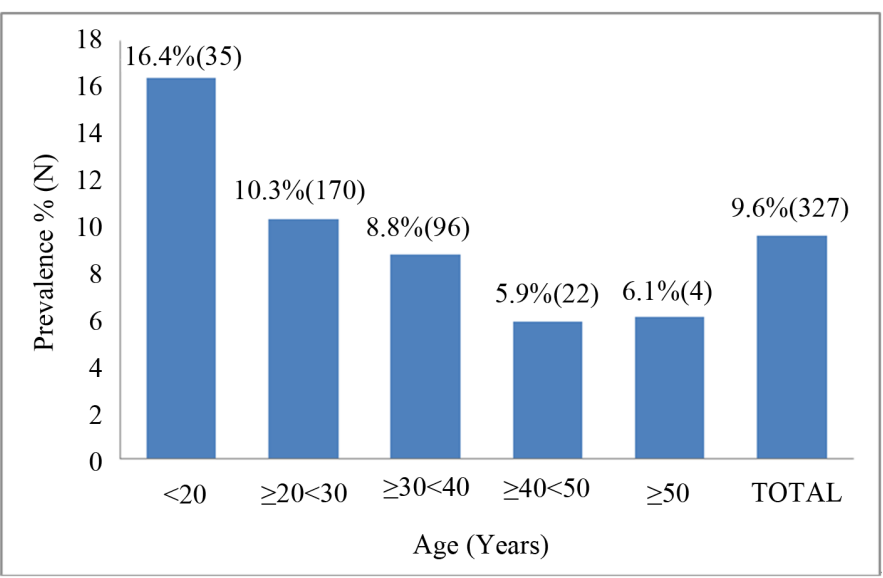

Figure 1. Age distribution of hepatitis B surface antigen sero-prevalence among blood donors at the Kintampo Municipal Hospital. 
valence however does support the possibility of horizontal transmission of the virus particularly among sexually active age groups [22].

Stratifying the prevalence data into various age groups, the study revealed an age effect on the prevalence of HBV among the studied population. The highest prevalence was seen among donors in age group $<20$ years (Figure 1). This agrees with a similar study where higher prevalence of HBsAg was observed in individuals aged between 11 to 20 years [23]. Khan and his colleagues further established that younger and older people are less frequently infected with HBV [23]. Majority of the donors who had positive HBsAg were less than 40 years, a finding which is in consonance with a study conducted by Castolo et al. and Alam et al. [24] [25]. Aside the fact the these age groups frequently involve in blood donation and hence their number may influence the prevalence, their constant exposure to the society cannot be overlooked since they have greater interaction among their peers, thereby predisposing them to contracting the disease.

Grouping the prevalence data into sex, an insignificantly higher prevalence was observed in males $(9.7 \%)$ compared to females (8.5\%). There are reports on the huge variation in gender participation in blood donation exercise [26] [27]. Generally, males donate blood more often than females, particularly in developing countries [28]. The reason has been attributed to socio-cultural influences and believes [29]-[31]. However, encouraging more females to participate in blood donation will be of immense benefit since they constitute the majority of the population.

\section{Conclusion}

The prevalence of HBsAg among blood donors at the Kintampo municipal hospital was relatively high (9.6\%) and could be higher in the general population of the municipality. This raises serious public health concerns about the quality and safety of blood transfusion in the municipality. The ratio of male to female blood donors was approximately 20:1. However, the probability of HBV infection was found to be dependent on age. Individuals less than 40 years donated blood the most, and they are the group more likely to be infected with HBV.

\section{Acknowledgements}

We thank the Kintampo Municipal Hospital for permitting the study, particularly the hospital laboratory staff.

\section{Recommendation}

The high prevalence observed among the blood donors suggests the possibility of relatively high rates of vertical transmission of the virus in the municipality. There must therefore be stringent measures to curtail mother to child transmission as well as early childhood infection of HBV. More effective methods should be employed in the screening of blood for transfusion since the high HBsAg sero-prevalence rate gives room for occult transmission and infection of patients via blood transfusion.

\section{Competing Interest}

None declared.

\section{Authors' Contributions}

Williams Walana conceived and developed the study protocol, and also analyzed the data. Patrick Hockey and Samuel Ahiaba aided in data collection. All authors contributed significantly to the development of the manuscript.

\section{References}

[1] WHO (2009) Hepatitis B Vaccines. Weekly Epidemiological Record.

[2] Ott, J.J., Stevens, G.A., Groeger, J. and Wiersma, S.T. (2012) Global Epidemiology of Hepatitis B Virus Infection: New Estimates of Age-Specific HBsAg Seroprevalence and Endemicity. Vaccine, 30, 2212-2219. http://dx.doi.org/10.1016/j.vaccine.2011.12.116

[3] Salisbury, D., Ramsay, M. and Noakes, K., Eds. (2006) Immunisation against Infectious Disease, London. The Stationary Office. 
[4] Caley, M., Fowler, T., Greatrex, S. and Wood, A. (2012) Differences in Hepatitis B Infection Rate between Ethnic Groups in Antenatal Women in Birmingham, United Kingdom, May 2004 to December 2008. Eurosurveillance, 17, 20228. http://www.eurosurveillance.org/ViewArticle.aspx?ArticleId=20228

[5] Kiire, C.F. (1996) The Epidemiology and Prophylaxis of Hepatitis B in Sub-Saharan Africa: A View from Tropical and Subtropical Africa. Journal of Gastroenterology and Hepatology, 38, S5-S12.

[6] Ghana Immunization Programme (2010) Comprehensive Multiyear Plan (2010-2014) in line with Global Immunization Vision and Strategies, 10-45.

[7] Taylor, J.M., Purcell, R.H. and Farci, P. (2013) Hepatitis D (Delta) Virus. In: Knipe, D.M. and Howley, P.M., Eds., Fields Virology, 6th Edition, Lippincott Williams \& Wilkins, Philadelphia.

[8] Tong, S., Li, J., Wands, J.R. and Wen, Y. (2013) Hepatitis B Virus Genetic Variants: Biological Properties and Clinical Implications. Emerging Microbes \& Infections, 2, e10. http://dx.doi.org/10.1038/emi.2013.10

[9] Tong, M.J., Hsu, L., Chang, P.W. and Blatt, L.M. (2011) Evaluation of Current Treatment Recommendations for Chronic Hepatitis B: A 2011 Update. Journal of Gastroenterology and Hepatology, 26, 829-835.

[10] Adams, D.H. and Hubscher, S.G. (2006) Systemic Viral Infections and Collateral Damage in the Liver. American Journal of Pathology, 168, 1057-1059. http://dx.doi.org/10.2353/ajpath.2006.051296

[11] Vinciguerra, M., Mazzoccoli, G., Piccol, C., Tataranni, T., Andriulli, A. and Pazienza, V. (2013) Exploitation of Host Clock Gene Machinery by Hepatitis Viruses B and C. World Journal of Gastroenterology, 19, 8902-8909. http://dx.doi.org/10.3748/wjg.v19.i47.8902

[12] Rehermann, B. and Nascimbeni, M. (2005) Immunology of Hepatitis B Virus and Hepatitis C Virus Infection. Nature Review. Immunology, 5, 215-229. http://dx.doi.org/10.1038/nri1573

[13] CDC (2010) Sexually Transmitted Diseases Treatment Guidline. http://www.cdc.gov/std/treatment/2010/vaccine.htm

[14] CDC (2008) Recommendations for Identification and Public Health Management of Persons with Chronic Hepatitis b Virus Infection. MMWR, 57, 9-11.

[15] Mast, E.E., Weinbaum, C.M., Fiore, A.E., Alter, M.J., Bell, B.P., Finelli, L., Rodewald, E.L., Douglas, M., Janssen, R.S. and Ward, J. (2005) A Comprehensive Immunization Strategy to Eliminate Transmission of Hepatitis B Virus Infection in the United States: Recommendations of the Advisory Committee on Immunization Practices (ACIP) Part 1: Immunization of Infants, Children, and Adolescents. MMWR Recommendations and Reports, 54, 1-31.

[16] MOH-Ghana (2006) National Blood Policy for the Health Sector. 5-25.

[17] World Health Organization (2006) Blood Transfusion Safety, Geneva. http://www.who.int/bloodsafety/en/Blood_Transfusion_Safety.pdf

[18] GSS (2012) 2010 Population and Housing Census Final Results. 1-15.

[19] Hou, J., Liu, Z. and Gu, F. (2005) Epidemiology and Prevention of Hepatitis B Virus Infection. International Journal of Medical Sciences, 2, 50-57. http://dx.doi.org/10.7150/ijms.2.50

[20] Te, H.S. and Jensen, D.M. (2010) Epidemiology of Hepatitis B and C Viruses: A Global Overview. Clinics in Liver Diseases, 14, 1-21. http://dx.doi.org/10.1016/j.cld.2009.11.009

[21] Lok, A.S. (2002) Chronic Hepatitis B. The New England Journal of Medicine, 346, 1682-1683. http://dx.doi.org/10.1056/NEJM200205303462202

[22] Gust, I.D. (1996) Epidemiology of Hepatitis B Infection in the Western Pacific and South East Asia. Journal of Gastroenterology and Hepatology, 38, S18-S23.

[23] Khan, F., Shams, S., Qureshi, D.I., Israr, M., Khan, H., Sarwar, T.M. and Ilyas, M. (2011) Hepatitis B Virus Infection among Different Sex and Age Groups in Pakistani Punjab. Virology Journal, 8, 225. http://dx.doi.org/10.1186/1743-422X-8-225

[24] Castolo, M.C., Ndez-Ruiz, L.H. and Ibarra-Robles, I.E., Rate, I.H.F.N. and Pena, J.E. (2001) Prevalence of Hepatitis B Virus Infection and Related Risk Factors in a Rural Community of Mexico. American Journal of Tropical Medicine and Hygiene, 65, 759-763.

[25] Alam, M.M., Zaidi, S.Z., Malik, S.A., Shaukat, S., Naeem, A., Sharif, S., Angez, M. and Butt, J.A. (2007) Molecular Epidemiology of Hepatitis B Virus Genotypes in Pakistan. BMC Infectious Diseases, 7, 115. http://dx.doi.org/10.1186/1471-2334-7-115

[26] Nkrumah, B., Owusu, M. and Averu, P. (2011) Hepatitis B and C Viral Infections among Blood Donors: A Retrospective Study from a Rural Community of Ghana. BMC Research Notes, 4, 529. http://dx.doi.org/10.1186/1756-0500-4-529

[27] Dongdem, T.J., Kampo, S., Soyiri, N.I., Asebga, N.P., Ziem B.J. and Sagoe, K. (2012) Prevalence of Hepatitis B Virus Infection among Blood Donors at the Tamale Teaching Hospital, Ghana (2009). BMC Research Notes, 5, 115. 
http://dx.doi.org/10.1186/1756-0500-5-115

[28] Saberton, P.J., Paez, A., Newbold, K.B. and Heddle, N.M. (2009) Geographical Variations in the Correlates of Blood Donor Turnout Rates: An Investigation of Canadian Metropolitan Areas. International Journal of Health Geographics, 8, 56. http://dx.doi.org/10.1186/1476-072X-8-56

[29] Salaudeen, A.G., Musa, O.I., Awoyemi, A.O., Bolarinwa, A.O., Adegboye, A.O. and Samuel, S.O. (2011) Community Survey on Blood Donation Practices in a Northern State of Nigeria. Journal of Preventive Medicine and Hygiene, 52, 21-25.

[30] Smith, A., Matthews, R. and Fiddle, J. (2011) Blood Donation and Community: Exploring the Influence of Social Capital. International Journal of Social Inquiry, 4, 45-63.

[31] Singh, B., Pandey, R.M., D’Souza, N., Anushyanthan, A., Krishna, V., Gupta, V., Chaudhary, M.M., Ganeshan, S., Jha, S., Uppal, S., Mehrara, V., Deepchand, R.D., Singh, Y., Hsia, K.M., Bhushan, S., Anand, V. and Singh, A.K. (2002) Knowlege, Attitudes and Socio-Demographic Factors Differentiating Blood Donors from Non-Donors in an Urban Slum of Delhi. Indian Journal of Community Medicine, 27, 118-123. 